\title{
РАЗВИТИЕ АУДИТОРСКОЙ ДЕЯТЕЛЬНОСТИ В УСЛОВИЯХ ЧЛЕНСТВА РОССИИ В ЕВРАЗИЙСКОМ ЭКОНОМИЧЕСКОМ СООБЩЕСТВЕ И ТАМОЖЕННОМ СОЮЗЕ 1
}

\begin{abstract}
Аннотация: В статье рассматривается актуальный вопрос развития аудиторской деятельности на современном этапе в условиях членства России в Евразийском экономическом сообществе и Таможенном союзе. Рассмотрень особенности понятийного аппарата в сфере аудита, выделена специифика правового регулирования обязательного аудита, анализируются проблемы унификации нацииональных законодательств государств-членов ЕврАзЭс и Таможенного союза и сформулированы рекомендации по их совериенствованию. Особое внимание уделено такому способу обеспечения должного уровня безопасности товаров, ввозимых на территорию Таможенного союза как аудит зарубежной официальной системы надзора. Анализ различных нормативных актов государств-членов ЕврАзЭС и Таможенного союза позволил автору статьи сделать вывод о том, что аудит представляет собой один из эффективных способов влияния на развитие экономики, однако нормативная база в данном секторе окончательно не сформирована и требует дальнейшего совершенствования при активном сотрудничестве государств-членов ЕврАзЭС и Таможенного союза.

Review: The article is devoted to the topical issue of audit development at the current stage within the framework of membership of Russia in the EurAsEC and the Customs Union. The author evaluates specific features of definition apparatus in the audit sphere, and singles out specific features of obligatory audit regulation, as well as the problems related to unification of national legislations of the Member States to the EurAsEC and the Customs Union, then she formulates the propositions for their improvement. Much attention is paid to audit of the foreign official supervision system as means to guarantee due security level of the goods imported to the territory of the Customs Union. Analysis of various normative acts of the Member States of the EurAsEc and the Customs Union allowed the author to make a conclusion that audit is one of efficient means of influence on economic development, however, the normative basis in this sector is not completely formed, and it needs further improvement with active cooperation of the EurAsEc and the Customs Union Member States. Ключевые слова: аудит, ЕврАзЭС, Таможенный союз, обязательный аудит, система надзора, безопасность продукиии, унификация, инстрекция, выездные проверки, стандарты
\end{abstract}

Keywords: audit, EurAsEC, the Customs Union, obligatory audit, supervision system, product security, unification, inspection, field audit, standard.

а сегодняшний день в условиях динамичного развития интеграционных процессов, расширения сферы международного сотрудничества, глобализации экономики очевидной является необходимость активного участия России в этих процессах на международной арене.

16 декабря 2011 года в Женеве был подписан Протокол ${ }^{2}$ о присоединении Российской Федерации к

\footnotetext{
${ }^{1}$ Данная статья (работа) подготовлена в рамках Программы стратегического развития ФГБОУ ВПО Московский государственный юридический университет имени О.Е. Кутафина (МГЮА); НИР «Государственное регулирование экономической деятельности в условиях членства России в ВТО, Евразийском экономическом сообществе и Таможенном союзе.», проект № 2.1.1.1.

2 «С3 РФ», 10.09.2012, №37, ст.4986
}

Марракешскому соглашению об учреждении Всемирной торговой организации (далее - ВТО) от 15 апреля 1994 года. Данный протокол был ратифицирован Российской Федерацией Федеральным законом от 21 июля 2012 года № 126 - Ф3³. Официальное вступление России в ВТО состоялось 22 августа 2012 года.

Присоединение России к ВТО было долгожданным явлением, которое, впрочем, вызывало дискуссии у многих специалистов. С одной стороны, признавая подобное членство определенной гарантией перспективного экономического сотрудничества, обеспечением открытости торговой политики, формированием

\footnotetext{
${ }^{3}$ «СЗ РФ», 23.07.2012, №30, ст.4177
} 
привлекательного инвестиционного климата для иностранных инвесторов, аналитики высказывали определенные опасения, связанные, например, с перспективой понижения конкурентоспособности отечественных компаний. Сегодня, по прошествии практически года с момента вступления России в ВТО, можно подвести если не итоги, то дать предварительную оценку дальнейшим перспективам сотрудничества, определить вектор развития предпринимательского сектора в новых условиях.

Российская Федерация является также участницей Евразийского экономического сообщества (далее ЕврАзЭС). 10 декабря 2000 года в Астане Республикой Беларусь, Республикой Казахстан, Кыргызской Республикой и Республикой Таджикистан был подписан Договор об учреждении Евразийского экономического сообщества ${ }^{4}$. В рамках ЕврАзЭС 6 октября 2007 года в Душанбе такими государствами как Российская Федерация, Республика Казахстан, Республика Беларусь был подписан Договор о создании единой таможенной территории иформировании таможенного союза 5 .

Сегодня все развитые государства уделяют особое внимание вопросам регулирования аудита. Так, в последние годы наблюдается устойчивая тенденция развития институтов саморегулирования, передача профессиональным сообществам полномочий государства в сфере регулирования. Однако именно государство создает мощную фундаментальную базу для развития тех или иных отраслей, обеспечивает необходимый уровень должного правового регулирования. В последние годы наблюдается неподдельный интерес к вопросам осуществления аудиторских проверок. Действительно, аудит играет важную роль в экономической деятельности. Так, известны случаи, когда крупные аудиторские организации подтверждали достоверность бухгалтерской отчетности хозяйствующих субъектов, находящихся на самом деле в состоянии банкротства. Инвесторы рассматривают аудиторское заключение как один из основных источников информации, позволяющий принять стратегически верное решение об инвестировании средств. Для того, чтобы аудиторское заключение являлось определенной гарантией, необходимо осуществление данного вида деятельности в соответствии со стандартами, как международными, так и национальными.

\footnotetext{
${ }^{4}$ «C3 РФ», 18.02.2002, №7, ст.632

5 «Бюллетень международных договоров», №7, июль, 2011
}

Таким образом, представляется важным с аналитической точки зрения обратиться к вопросам правовой регламентации аудита в условиях членства России в Евразийском экономическом сообществе и Таможенном союзе.

В первую очередь обратимся к законодательству некоторых государств-членов ЕврАзЭС.Так, например, закон Республики Беларусь от 8 ноября 1994 года № 3373-XII «Об аудиторской деятельности» ${ }^{6}$ определяет аудиторскую деятельность как предпринимательскую деятельность по независимой проверке (аудиту) бухгалтерского учета и бухгалтерской (финансовой) отчетности и других документов ряда хозяйствующих субъектов в целях выражения мнения о достоверности бухгалтерской (финансовой) отчетности и соответствии совершенных финансовых (хозяйственных) операций законодательству. Однако совсем скоро, а именно с 1 января 2014 года, в силу вступят положения нового закона Республики Беларусь от 12 июля 2013 года №56-3 «Об аудиторской деятельности» (далее - Закон об аудиторской деятельности Республики Беларусь), который будет отвечать требованиям мирового сообщества в области проведения аудита. Так, новый Закон об аудиторской деятельности Республики Беларусь определяет, что аудиторская деятельность является предпринимательской деятельностью по оказанию аудиторскими организациями, аудиторами, осуществляющими деятельность в качестве индивидуальных предпринимателей, аудиторских услуг.

Согласно Закону Республики Казахстан от 20 ноября 1998 года №304-І«Об аудиторской деятельности» ${ }^{8}$ (далее-Закон об аудиторской деятельности Республики Казахстан) под аудиторской деятельностью следует понимать предпринимательскую деятельность по проведению аудита финансовой отчетности и прочей информации, связанной с финансовой отчетностью, и предоставлению услуг по профилю деятельности.

\footnotetext{
${ }^{6}$ Текст закона Республики Беларусь от 8 ноября 1994 года №3373XII «Об аудиторской деятельности» размещен на официальном сайте Министерства финансов Республики Беларусь// URL:http:// www.minfin.gov.by/rmenu/auditing/audit/ukaz/

7 Текст закона Республики Беларусь от 12 июля 2013 года №56-3 «Об аудиторской деятельности» размещен на официальном сайте Министерства финансов Республики Беларусь// URL:http://www. minfin.gov.by/rmenu/auditing/audit/ukaz/

${ }^{8}$ Текст закона Республики Казахстан опубликован на официальном сайте Министерства финансов Республики Казахстан //URL:http://www.minfin.gov.kz/irj/portal/anonymous?NavigationT arget=ROLES://portal_content/mf/kz.ecc.roles/kz.ecc.anonymous/ kz.ecc.anonymous/kz.ecc.anonym_activities/activities/legislation_fldr
} 
DOI: $10.7256 / 1811-9018.2013 .10 .9424$

При цитировании этой статьи сноска на dоі обязательна

\section{Право и политика 10 (166) $\bullet 2013$}

Закон Республики Таджикистан от 22 июля 2013 года №993 «Об аудиторской деятельности» (далее - Закон Республики Таджикистан) определяет аудиторскую деятельностькак предпринимательскую деятельность по проведению аудита и других услуг, связанных с ней, осуществляемую индивидуальным аудитором или аудиторской организацией. Следует отметить, что положения нового Закона об аудиторской деятельности в Республике Таджикистан учли рекомендации по гармонизации законодательства государств-членов ЕврАзЭС в сфере аудиторского контроля, разработанные Межпарламентской ассамблеей евразийского экономического сообщества ${ }^{10}$. В данных рекомендациях было отражено, что законодательство Республики Таджикистан не разграничивает понятия «аудит» и «аудиторская деятельность», считая их тождественными, что представляется в корне неверным, так как аудиторская деятельность является более широким понятием по сравнению с аудитом, в связи с чем, предлагалось провести разграничение этих терминов. Новый закон об аудиторской деятельности Республики Таджикистан устранил несовершенства понятийного аппарата.

Таким образом, можно сделать вывод о том, что наблюдается устойчивая тенденция в унификации законодательства государств-участников ЕврАзЭС. Так, все нормативные правовые акты в сфере аудита квалифицируют аудиторскую деятельность в качестве предпринимательской. Хотя в литературе высказывались и иные точки зрения, например, о квалификации аудиторской деятельности как профессиональной ${ }^{11}$.

Государственное регулирование экономической деятельности в сфере аудита проявляется в регламентации проведения обязательного аудита. Чаще всего законодатель определяет цель аудита как выражение мнения о достоверности финансовой (бухгалтерской) отчетности аудируемых лиц. Указанная цель придает аудиторской деятельности общественно значимый характер, что особенно явно проявляется при проведении как раз обязательного аудита. Нормативные правовые акты в сфере аудиторской деятельности всех государств

\footnotetext{
${ }^{9}$ Текст закона Республики Таджикистан от 22 июля 2013 года № 993 «Об аудиторской деятельности» размещен на сайте Национального центра законодательства при президенте Республики Таджикистан// http://www.mmk.tj/ru/legislation/ legislation-base/250/

${ }^{10}$ Приложение 1 к постановлению комиссии от 16.05.2012 №6.

${ }^{11}$ См. подробнее ст. Аганиной Р.Н. «Субъекты профессиональной аудиторской деятельности» в журнале «Право и политика», №2, 2009, C. 297
}

- членов ЕврАзЭС определяют порядок проведения обязательного аудита. Однако определения самого понятия обязательного аудита содержатся лишь в нормативных актах отдельных государств. Так, закон об аудиторской деятельности Республики Таджикистан определяет обязательный аудит как ежегодную проверку бухгалтерского учета и финансового отчета юридических лиц. В соответствии со статьей 17 нового Закона об аудиторской деятельности Республики Беларусь обязательный аудит бухгалтерской (финансовой) отчетности - аудит бухгалтерской (финансовой) отчетности, обязательность проведения которого установлена Законом об аудиторской деятельности и другими законодательными актами Республики Беларусь. Примечательно, что кроме указанных в статье 17 Закона об аудиторской деятельности Республики Беларусь хозяйствующих субъектов, обязательный аудит проводится в отношении иных организаций, у которых объем выручки от реализации товаров (выполнения работ, оказания услуг) за предыдущий отчетный год превышает в эквиваленте 5000000 евро по официальному курсу белорусского рубля к евро, установленному Национальным банком Республики Беларусь на 31 декабря предыдущего отчетного года. Очевидно, что увеличение порога до указанной суммы связано с освобождением от проведения обязательного аудита субъектов малого предпринимательства. Данный вопрос является достаточно дискуссионным, высказываются диаметрально противоположные позиции по данному вопросу, есть и активные противники установления подобного высокого критерия. В качестве примера можно сослаться на пункт 3.1.16 доклада «О действующей в РФ системе государственного регулирования и саморегулирования аудиторской деятельности. Предложения по реформированию» ${ }^{12}$, в соответствии с которым освобождение от обязательного аудита субъектов малого предпринимательства «лишает пользователей возможности получения достоверной информации о финансовом состоянии дел в этом секторе экономики, противоречит международным соглашениям, поддержанным Россией, в отношении применения стандартов бухгалтерского учета и усиления роли аудита в частном секторе».

\footnotetext{
12 Данный доклад был разработан Советом по общественному надзору за развитием бухгалтерского учета, бухгалтерской (финансовой) отчетности, организацией государственного регулирования и саморегулирования аудиторской деятельности в PФ// URL: http:// sovnadzor.ru/
} 
Следует отметить, что Закон Республики Таджикистан достаточно подробно классифицирует виды аудита и кроме обязательного аудитаопределяет понятие внутреннего аудита, что, безусловно, следует оценить с положительной стороны. Так, И.В. Ершова отмечает, что «В настоящее время в России отсутствует адекватное нормативное правовое регулирование внутреннего аудита. Это затрудняет подготовку квалифицированных специалистов, не стимулирует создание служб внутреннего аудита и повышение уровня внутреннего аудита в тех организациях, где они функционируют» $\rangle^{13}$. Полагаем, что национальные законодательства иных государств - членов ЕврАзЭС могли бы закрепить в своих нормативных актах понятие внутреннего аудита.

Государства - члены ЕврАзЭС оказывают большое количество услуг, в том числе и аудиторских, порядок оказания которых регламентирован массивом различных нормативных правовых актов. В связи с этим Бюро Межпарламентской ассамблеи евразийского экономического сообщества были разработаны «Рекомендации по приведению законодательства республики Беларусь, Республики Казахстан, Российской Федерации в соответствие с Соглашением о торговле услугами и инвестициях в государствах-участниках Единого экономического пространства» ${ }^{14}$. Данное соглашение нацелено на создание наиболее благоприятных условий для взаимной торговли услугами, упрощения порядка торговли услугами, формирования единой цели и принципов в данной сфере, что в совокупности должно привести к экономическому росту стран-участниц. Следует обратить особое внимание на положения статьи 16 данного Соглашения, где говорится о необходимости унификации национальных законодательств с учетом международных принципов и правил. В связи с этим хотелось бы отметить тот факт, что ранее национальные законодательства принципиально отличались в подходе к государственному регулированию аудиторской деятельности. Так, в большинстве стран аудиторская деятельность являлась лицензируемой, в то время как в РФ был принят Ф3 от 01.12.2007 года № 315- Ф3 «О саморегулируемых организациях» ${ }^{15}$ и в дальнейшем Ф3 от

\footnotetext{
${ }^{13}$ И.В. Ершова, А.А.Ершов. Правовое регулирование аудиторской деятельности в Российской Федерации.М.Юриспруденция, 2011. C. 172

14 «С3 РФ», 23.01.2012, N 4, ст. 453

15 «СЗ РФ», 03.12.2007, №49, ст. 6076
}

30.12.2008 №307-Ф3 «Об аудиторской деятельности» ${ }^{16}$, согласно которому лицензирование было заменено обязательным членством аудиторских организаций и аудиторов в саморегулируемых организациях. Сегодня мы наблюдаем изменения и в данной сфере. Так, нормы нового закона об аудите республики Беларусь определяют, что для осуществления аудиторской деятельности физическому лицу необходимо пройти аттестацию для получения квалификационного аттестата аудитора. В рассматриваемом законе в качестве одного из требований к физическому лицу, претендующему на получения квалификационного аттестата аудита,является наличие высшего юридического или экономического образования. Само по себе данное требование является общепризнанной нормой и встречается в законодательстве всех стран. Однако, Закон об аудиторской деятельности Республики Беларусь, в отличие, например, от российского законодательства уточняет в статье 24 , что физическое лицо, получившее соответствующее образование за рубежом, допускается к прохождению аттестации на право получения квалификационного аттестата аудитора при наличии выданного Министерством образования Республики Беларусь свидетельства о признании документа об образовании, выданного в иностранном государстве, и установлении его эквивалентности документу об образовании Республики Беларусь. Полагаем, что в условиях унификации законодательства аналогичное требование может быть закреплено на федеральном уровне и в РФ.

На особую роль аудита в рамках масштабной экономической интеграции обращают внимание на властных уровнях в различных сферах деятельности. Так, 5 июля в Евразийской экономической комиссии состоялась встреча директора Департамента санитарных, фитосанитарных и ветеринарных мер ЕЭК Олега Арнаутова с атташе по сельскому хозяйству Посольства Республики Чили Пабло Бараона по вопросам взаимодействия между Евразийской экономической комиссией и Республикой Чили в сфере санитарных и фитосанитарных мер. В процессе встречи участники обсудили проведение аудиторских проверок чилийских предприятий рыбной и мясоперерабатывающей отраслей - поставщиков соответствующих товаров на рынок Таможенного союза. Олег Арнаутов отметил: «Мы считаем аудит одной из важных форм сотрудни-

${ }^{16}$ «Российская газета», N 267, 31.12.2008 
DOI: $10.7256 / 1811-9018.2013 .10 .9424$

При цитировании этой статьи сноска на доі обязательна

\section{Право и политика $10(166) \cdot 2013$}

чества ответственных органов наших стран и ЕЭК с уполномоченнылм в сфере санитарных и фитосанитарных мер органами Чили». Чилийская сторона высказала заинтересованность в участии в подобных проверках экспертов Евразийской экономической комиссии. На встрече названы сроки проведения аудиторских проверок. Аудит чилийских предприятий рыбной отрасли намечен на вторую половину 2013 года, мясоперерабатывающей отрасли - на 2014 год. ${ }^{17}$

Действительно, на сегодняшний день одним наиболее эффективным способом обеспечения должного уровня безопасности товаров, ввозимых из третьих стран на территорию Таможенного союза является аудит зарубежной официальной системы надзора.

В Положении о едином порядке проведения совместных проверок объектов и отбора проб товаров (продукции), подлежащих ветеринарному контролю (надзору) $)^{18}$ (далее - Положение №834) было отмечено, что после присоединения России к ВТО основополагающим принципом, используемым странами - членами Таможенного союза для обеспечения безопасности при импорте, будет являться проведение аудита зарубежной официальной системы надзора.

Введение такой меры как аудит зарубежной официальной системы надзора позволит минимизировать количество проверок предприятий, осуществляющих поставку подконтрольных товаров.

Аудит зарубежной официальной системы надзора представляет собой процедуру определения способности зарубежной официальной системы надзора обеспечивать уровень безопасности подконтрольных товаров как минимум эквивалентный установленному требованиями ТС.

В соответствии с пунктом «к» статьи 4 раздела II Положения №834 подконтрольными товарами следует считать животных и продукцию животного происхождения, включенных в Единый перечень товаров, подлежащих ветеринарному контролю (надзору) ${ }^{19}$.

Положение № 834 регламентирует достаточно сложный порядок проведения аудита зарубежной офи-

\footnotetext{
$17 \mathrm{http}: / / \mathrm{ww}$ w.eurasiancommission.org/ru/nae/news/ Pages/05-07-2013-4.aspx

18 Утверждено Решением Комиссии Таможенного союза от 18 октября 2011 года №834

${ }^{19}$ Решением Комиссии Таможенного союза от 23.09.2011 N 810 установлен перечень отдельных товаров, включенных в Единый перечень товаров, подлежащих ветеринарному контролю (надзору), в отношении которых уполномоченные органы Российской Федерации не осуществляют ветеринарный контроль.
}

циальной системы надзора. В первую очередь следует обратить внимание на то, что инспекторы ${ }^{20}$, осуществляющие аудит должны различать две ситуации:

а)в отношении стран, из которых не осуществлялся импорт подконтрольных товаров на таможенную территорию ТС;

б) в отношении стран, из которых осуществлялся импорт подконтрольных товаров на таможенную территорию ТС.

Для того, чтобы начать процедуру аудита компетентному органу третьей стороны необходимо направить обращение в уполномоченный орган государства - члена ТС, обозначив область проведения аудита. Оценивая зарубежную официальную систему надзора, инспекторы должны принимать во внимание сложившуюся историю торговли с данной страной, а также информацию, которой обладает соответствующий уполномоченный орган. К данной информации следует относить: нормативную документацию, обеспеченность персоналом, организацию, структуру, компетенцию компетентного органа третьей страны, систему контроля здоровья животных и систему защиты здоровья людей. Что касается критериев оценки, которые должны быть использованы при оценке зарубежной официальной системы надзора, то данные критерии устанавливаются различными правовыми актами, например, положениями Санитарного кодекса наземных животных и Санитарного кодекса водных животных, другими международными стандартами и руководствами, признаваемыми ВТО.

Анализ Положения №834 позволяет сделать вывод о том, что процедура аудита зарубежной официальной системы надзора включает в себя несколько этапов:

а) осуществление документарного анализа

б) проведение инспекций/выездных проверок

в) публикация отчета (предварительного и окончательного)

г) принятие решения о включении третьей страны в Перечень

На первой стадии уполномоченный орган государства-члена ТС направляет в адрес третьей страны запрос о предоставлении законодательных и иных документов, необходимых для проведения оценки.

\footnotetext{
${ }^{20}$ Инспектор - официальное уполномоченное лицо уполномоченного органа государства - члена ТС или компетентного органа третьей стороны. Уполномоченный орган - государственный орган Стороны, обладающий полномочиями по разработке правовых актов и/или применению законодательства (или обеими функциями) по проведению проверок
} 
Кроме того может быть проведено своеобразное анкетирование. Так, направляется вопросник для получения дополнительной информации, например, о методах и приемах практической работы компетентного органа третьей страны. Данный этап заканчивается принятием решения о том является ли зарубежная официальная система регулирования в отношении соответствующих товаров способной обеспечить, в целом, уровень защиты как минимум эквивалентный требованиям ТС. При положительном решении наступает вторая стадия процедуры проведения аудита зарубежной официальной системы надзора.

Второй этап связан с проведением инспекций, выездных проверок. По общему правилу (если иное не предусмотрено соглашением сторон) уполномоченный орган государства-члена ТС обязан проинформировать уполномоченные органы иных государств-членов ТС о предстоящем визите в целях формирования группы инспекторов и координации времени. Следует отметить, что если иные государства-члены ТС не сообщают о своем неучастии в проведении аудита либо просто не отвечают, то визит может быть осуществлен инспекторами только одного государства-члена ТС. Кроме непосредственно инспекторов в процедуре проведения аудита могут участвовать эксперты, являющиеся представителями государственных органов и учреждений. Целью привлечения данных специалистов является оказание содействия по ряду вопросов, например, консультирование по вопросам законодательства третьей страны, обучение персонала, и т.п. Полагаем, что Положение №834 должно конкретизировать, какие именно квалификационные требования должны предъявляться к лицам, осуществляющим проведение инспекций, и более подробно определить правовой статус инспектора.

Третий этап включает составление предварительного отчета, с заключением о наличии или отсутствии эквивалентности. В течение двух месяцев уполномоченные органы государств-членов ТС, включая и те государства-члены ТС, которые не принимали участие в аудите, а также компетентные органы третьей страны могут направлять дополнительные данные и разъяснения относительно информации и выводов предварительного отчета. Окончательная форма отчета с учетом полученной дополнительной информации должна быть составлена в течение 2 месяцев. Окончательный отчет должен содержать заключение о том, обеспечивает ли зарубежная официальная система надзора уровень за- щиты, как минимум, эквивалентный уровню защиты в соответствии с требованиями ТС. Таким образом, в отчете может содержаться положительное или отрицательное заключение. Положительное заключение является основанием для принятия решения о включении третьей страны в Перечень стран-экспортеров, обладающих эквивалентным уровнем защиты в отношении данного вида подконтрольных товаров. В том случае, если окончательный отчет содержит отрицательное заключение, то государства-члены ТС могут рассмотреть вопрос о предоставлении третьей стране права предоставлять гарантии о соответствии подконтрольных товаров, производимых конкретным предприятием (предприятиями) данной третьей страны, или проинформировать компетентный орган третьей страны о том, что предприятия данной третьей страны могут быть включены в Реестр предприятий третьих стран исключительно в результате положительных результатов проверки производства таких предприятий инспекторами ТС. Подобное решение принимается на основании ряда критериев, таких как, например, уровень развития компетентного органа третьей страны; уровень обоснованности гарантий, предоставлявшихся компетентным органом данной третьей страны.

Можно выделить два вида аудита зарубежной официальной системы надзора: первоначальный и повторный. Порядок проведения процедуры первоначального аудита был рассмотрен выше. Комиссия ТС принимает решение о проведении повторного аудита официальной системы надзора третьей страны не чаще, чем один раз в год. Однако если официальная система контроля третьей страны не признана способной обеспечить уровень защиты как минимум эквивалентный уровню защиты, предусмотренному требованиям ТС, компетентный орган этой страны может повторно обратиться для проведения аудита в любое время после проведения мероприятий по устранению выявленных недостатков. При проведении повторного аудита следует учитывать целесообразность такого рода проверки, а также принимать во внимание необходимость уменьшения количества информации, предоставляемой компетентным органам третьей страны.

Конечно, на сегодняшний день, существуют определенные проблемы осуществления аудита зарубежной официальной системы надзора, что связано с переходным этапом, когда система проведения проверок не является полностью отработанной. Так, Федеральная служба по ветеринарному и фитоса- 
DOI: $10.7256 / 1811-9018.2013 .10 .9424$

При цитировании этой статьи сноска на dоі обязательна

\section{Право и политика $10(166) \cdot 2013$}

нитарному надзору опубликовала информационное сообщение «О схеме совместных действий компетентных органов стран-членов ТС и третьих стран - экспортеров на начальный период после завершения процесса присоединения к ВТО $»^{21}$, в котором отмечено, что «третьи страны должны понимать, что аудит может быть проведен не в те сроки, когда третья страна этого желает, а позднее (возможно значительно позднее), если к моменту подачи ею заявки на проведение аудита Россельхознадзор уже будет иметь такое большое количество аналогичных заявок от других третьих стран, что не сможет обеспечить проведение аудита в данной третьей стране в желательный срок кадровыми и/или финансовыми ресурсами».

На наш взгляд, Положение №834, безусловно, заложило концептуальные основы проведения аудита зарубежной официальной системы надзора, но требует дальнейшего совершенства и доработки. Так, общественно значимые виды деятельности должны осуществляться в соответствии с определенными принципами, являющимися основополагающим началом для данной сферы. Полагаем, что при проведении аудита зарубежной официальной системы надзора таковыми будут являться: независимость, открытость, профессионализм, формирование единой системы требований к проведению аудита. Наиболее важным является принцип независимости, так как на результаты проводимой проверки не должны влиять какие-либо внешние факторы. Исходя из вышесказанного, под аудитом зарубежной официальной системы надзора следует понимать независимую проверку способности зарубежной официальной системы надзора обеспечивать уровень безопасности подконтрольных товаров как минимум эквивалентный установленному требованиями ТС. Следует указать также и цель проведения аудита. Цель аудита - оценка соответствия зарубежной официальной системы надзора требованиям, установленным ТС.

Итак, анализ различных нормативных актов государств-членов ЕврАзЭс и Таможенного союза позволяет сделать вывод о том, что аудит представляет собой один из эффективных способов влияния на развитие экономики, однако нормативная база в данном секторе окончательно не сформировалась и требует дальнейшего совершенствования при активном сотрудничестве государств-членов ЕврАзЭС и Таможенного союза.

\section{Библиография:}

1. Аганина Р.Н. «Субъекты профессиональной аудиторской деятельности» // «Право и политика», №2, 2009, С. 297

2. И.В. Ершова, А.А.Ершов. Правовое регулирование аудиторской деятельности в Российской Федерации.М.Юриспруденция, 2011. С.17

\section{References (transliteration):}

1. Aganina R.N. «Sub”ekty professional'noi auditorskoi deyatel'nosti» // «Pravo i politika», №2, 2009, S. 297

2. I.V. Ershova, A.A.Ershov. Pravovoe regulirovanie auditorskoi deyatel'nosti v Rossiiskoi Federatsii.M.Yurisprudentsiya, 2011. S.17

21 Текст информационного письма опубликован на официальном сайте Россельхознадзора// http://www.fsvps.ru/fsvps/news/5093.html 